(UC); azathioprine (41.9\%) and infliximab (29.8\%) were the most frequently used drugs; 10 patients (4.5\%) were taking glucocorticoids, $104(46.8 \%)$ had been previously treated with glucocorticoids and 65 (29.3\%) had already been exposed to high doses of glucocorticoids (prednisolone equivalent dose $\geq 7.5 \mathrm{mg} / \mathrm{day}$ ). Ten patients $(4.5 \%)$ had previous fragility fractures and $32(14.4 \%)$ fulfilled diagnostic criteria of osteoporosis by DXA (T score $\leq-2.5)$. One hundred eightyone $(81.5 \%)$ patients exhibited low levels of 25 -hydroxy vitamin $D(<30 \mathrm{ng} / \mathrm{mL})$, $24(10.8 \%)$ had high levels of parathormone and $150(67.6 \%)$ showed elevated serum concentrations of beta-carboxy-terminal type-1 collagen crosslinks (betaCTX). Three patients (1.4\%) were under treatment with bisphosphonates and 18 $(8.1 \%)$ were taking calcium and/or vitamin D supplements.

Of interest, serum levels of albumin correlated negatively with beta-CTX ( $r=-$ $0.401 ; p<0.001)$ and positively with osteocalcin $(r=0.259 ; p<0.001)$. Correlations between clinical/analytical variables and BMD are presented in Table 1.

Patients under glucocorticoids had lower mean total hip BMD $(0.874 \pm 0.159$ vs $1.008 \pm 0.176 ; p=0.022)$ and femoral neck $B M D$ values $(0.797 \pm 0.174$ vs $0.933 \pm 0.179 ; p=0.014)$ in comparison with the group of patients that were not taking glucocorticoids.

No statistically significant differences in BMD values were found between the following subgroups: DC vs UC; normal vs low levels of 25-hydroxy vitamin D; patients exposed vs not exposed to high doses of glucocorticoids.

Table 1. Correlations between clinical/analytical variables and the BMD in an IBD population (BMD: Bone Mineral Density; IBD: Inflammatory Bowel Disease; n.s. not significant).

\begin{tabular}{lccc}
\hline & Total hip BMD & Femoral neck BMD & Lumbar Spine BMD \\
\hline Age & $\mathrm{r}=-0.356 ; \mathrm{p}<0.001$ & $\mathrm{r}=-0.469 ; \mathrm{p}<0.001$ & $\mathrm{r}=-0.259 ; \mathrm{p}<0.001$ \\
Age at IBD diagnosis & $\mathrm{r}=-0.254 ; \mathrm{p}<0.001$ & $\mathrm{r}=-0.327 ; \mathrm{p}<0.001$ & $\mathrm{r}=-0.226 ; \mathrm{p}=0.001$ \\
IBD duration & $\mathrm{r}=-0.147 ; \mathrm{p}=0.031$ & $\mathrm{r}=-0.218 ; \mathrm{p}=0.001$ & $\mathrm{n} . \mathrm{s}$. \\
Hemoglobin & $\mathrm{r}=0.249 ; \mathrm{p}<0.001$ & $\mathrm{r}=0.209 ; \mathrm{p}=0.002$ & $\mathrm{n} . \mathrm{s}$. \\
Albumin & $\mathrm{r}=0.189 ; \mathrm{p}=0.005$ & $\mathrm{r}=0.208 ; \mathrm{p}=0.002$ & $\mathrm{n} . \mathrm{s}$. \\
Erythrocyte sedimentation rate & $\mathrm{r}=-0.231 ; \mathrm{p}=0.001$ & $\mathrm{r}=-0.206 ; \mathrm{p}=0.003$ & $\mathrm{n} . \mathrm{s}$. \\
\hline
\end{tabular}

Conclusion: Our results show an important prevalence of undiagnosed and untreated osteoporosis in patients with IBD. Stronger correlations were found between clinical/analytical variables and femoral neck BMD. Of note are the weak correlations of BMD with acute-phase markers (negative correlation with erythrocyte sedimentation rate and positive correlations with hemoglobin and albumin) and of nutritional status (evaluated by albumin) with bone markers (negative correlation with the bone reabsorption marker beta-CTX and positive correlation with the bone formation marker osteocalcin).

Disclosure of Interests: None declared.

DOI: 10.1136/annrheumdis-2021-eular.494

\section{AB0609 RADIOFREQUENCY ECHOGRAPHIC MULTI- SPECTROMETRY FOR THE ASSESSMENT OF BOTH FEMORA IN PREGNANT WOMEN}

E. Kirilova ${ }^{1}$, N. Kirilov ${ }^{2}$, S. Vladeva ${ }^{3} .{ }^{1}$ UMBAL Dr. Georgi Stranski, Rheumatology, Pleven, Bulgaria; ${ }^{2}$ UMBAL Dr. Georgi Stranski, Orthopedics and Traumatology, Pleven, Bulgaria; ${ }^{3}$ Trakia University, Rheumatology, Stara Zagora, Bulgaria

Background: Radiofrequency Echographic Multi-Spectrometry (REMS) is a non-ionizing innovative approach for the assessment of REMS- ${ }_{\text {bas }}$ bone mineral density (BMD) of the axial skeleton. The principle of the REMS technology is based on the analysis of native raw unfiltered ultrasound signals during an echographic scan of the lumbar spine or the femoral neck [1]. Several studies demonstrated the high concordance with dual energy X-ray absorptiometry (DXA) in terms of measured BMD with this novel technology [2,3]. In previous published literature it was envisaged to apply this technology for the examination of the axial bone density in pregnant women. Pregnancy-associated bone loss has been demonstrated as decreased bone mineral density (BMD) in previous studies [4].

Objectives: The aim of the current study is to compare the BMD values of both femora between pregnant and non-pregnant women matched for age and BMI using the novel REMS technology.

Methods: Of total fifty women twenty pregnant women (40\%) and thirty non-pregnant women $(60 \%)$ were included in the study. The mean age of the pregnant women was 32 years \pm 5 standard deviations (SD), (range 25-41 years) and the mean age of the non-pregnant women was 30 years \pm 6 standard deviations (SD), (range 24-39 years). REMS approach was used to assess REMSBMD and REMS- Z-score values of the femoral neck. Furthermore, body mass index (BMI) and gestational age in weeks were evaluated.

Results: The mean BMI of the pregnant women was $26 \mathrm{~kg} / \mathrm{m}^{2} \pm 7 \mathrm{~kg} / \mathrm{m}^{2}$ (range $14 \mathrm{~kg} / \mathrm{m}^{2}-42 \mathrm{~kg} / \mathrm{m}^{2}$ ) and those of the non-pregnant women was $25 \mathrm{~kg} / \mathrm{m}^{2} \pm 5 \mathrm{~kg} / \mathrm{m}^{2}$ (range $16 \mathrm{~kg} / \mathrm{m}^{2}-35 \mathrm{~kg} / \mathrm{m}^{2}$ ). The mean gestational age was 20 weeks' gestation \pm 5 weeks' gestation (range 13-27 weeks' gestation). REMS- mean BMD of the left femoral neck of the pregnant women was $0.793 \mathrm{~g} / \mathrm{cm}^{2} \pm 0.167 \mathrm{~g} / \mathrm{cm}^{2}$ (range $0.563 \mathrm{~g} / \mathrm{cm}^{2}-1.154 \mathrm{~g} / \mathrm{cm}^{2}$ ). REMS- mean BMD of the right femoral neck of the pregnant women was $0.828 \mathrm{~g} / \mathrm{cm}^{2} \pm 0.153 \mathrm{~g} / \mathrm{cm}^{2}$ (range $0.570 \mathrm{~g} / \mathrm{cm}^{2}-1.161 \mathrm{~g} /$ $\mathrm{cm}^{2}$ ). After comparing left femoral neck BMD with the right femoral neck BMD of the pregnant women, we found a linear correlation $(R=0.764)$. Left femoral neck BMD value $\left(0.793 \mathrm{~g} / \mathrm{cm}^{2}\right)$ of the pregnant women was significantly lower than those of the non-pregnant women $\left(0.854 \mathrm{~g} / \mathrm{cm}^{2}\right), p=0.002$. The mean left femora Z-score of the pregnant women (-0.1 SD with range -2.5 SD-2.9 SD) was also significantly lower compared to those of the non-pregnant women (1.2 SD with range $-1.5 \mathrm{SD}-3.1 \mathrm{SD}), \mathrm{p}=0.003$.

Conclusion: This is the first study which provides data about BMD and Z-score values of both femora in pregnant women assessed with the radiation-free REMS technology. Pregnant women demonstrated significantly lower femoral neck BMD values and Z-scores compared to those of the non-pregnant women. Innovative REMS method could be very helpful for making decision about the treatment of pregnant women who are at risk of lower BMD due to concomitant diseases and/ or treatment associated with osteoporosis.

\section{REFERENCES:}

[1] Casciaro S, Conversano F, Pisani P, Muratore M. New perspectives in echographic diagnosis of osteoporosis on hip and spine. Clin Cases Miner Bone Metab. 2015; 12(2):142-150.

[2] Nikolov M, Nikolov N. AB0908 Assessment of the impact of the lean mass with body composition by dual-energy $x$-ray absorptiometry on the bone mineral density. Annals of the Rheumatic Diseases 2020; 79:1756.

[3] Chakova M., Chernev D., Kashukeeva P., Krustev P., Abedinov F. Lumbar Sympathectomy - Literature Review. International Journal of Science and Research (IJSR) Volume 7 Issue 8, August 2018 ISSN (Online): 2319-7064.

[4] Degennaro, V. A.; Cagninelli, G.; Lombardi, F. A. "VP34.12: First assessment of maternal status during pregnancy by means of radiofrequency echographic multi-spectrometry technology". Ultrasound in Obstetrics \& Gynecology. 2020, 56 (S1): 199

Disclosure of Interests: None declared.

DOI: 10.1136/annrheumdis-2021-eular.1061

\section{AB0610 NORMOCALCAEMIC HYPERPARATHYROIDISM AND BONE HEALTH - WORSE THAN ANTICIPATED?}

D. Masieh ${ }^{1}$, S. Deshpande ${ }^{1}$, M. K. Nisar ${ }^{1} .{ }^{1}$ Luton and Dunstable University Hospital, Rheumatology, Luton, United Kingdom

Background: Since the formal recognition of normocalcaemic hyperparathyroidism (nHPT) as a distinct entity in 2008 , several studies have been published describing the characteristics of these individuals. Controversy exists regarding diagnostics and the role of parathyroidectomy in such cases. A chief reason for lack of consensus is the disagreement among experts regarding the potential complications and a bias towards perhaps benign nature of this condition.

Objectives: In order to understand the challenges posed by this cohort, we aim to characterise these patients at presentation to our metabolic bone diseases unit with a focus on bone health.

Methods: We interrogated our departmental database and undertook retrospective analysis of all patients presenting to metabolic bone service at our large university teaching hospital with a catchment population of 350,000 . Individuals were included in the survey based on criteria of Vit $D>70 \mathrm{nmol} / \mathrm{L}$, normal calcium $(2.20-2.60 \mathrm{mmol} / \mathrm{L})$, eGFR $>60 \mathrm{ml} / \mathrm{min}$ and $\mathrm{PTH}>6.9 \mathrm{pmol} / \mathrm{L}$ measured twice at least three months apart.

Results: Over six months review period, of 134 referrals, 42 (31\%) were identified with nHPT. Follow up duration was two years. Mean age was 60 years (25-86). 38 (90\%) were women with 31 (81\%) post menopause. $34(80 \%)$ were of Caucasian descent. All had comorbidities with median of five (1-14). Polypharmacy ( $>4$ prescribed medicines) was common $(36 / 42,85 \%)$ with mean of seven prescribed medications (0-22). Mean Vit D was 88 (70.4-133.6), calcium 2.43 (2.26-2.58), creatinine 69.8 (48-115) and PTH 8.8 (7.2-14.2). Ten (24\%) had already had fragility fractures with mean of two (0-4). 21 had DXA scan with mean T score of $-3.78(-2.1-6.0)$. 13/21(31\%) had osteoporosis. Oral and IV bisphosphonates, denosumab and teriparatide were prescribed to 12 (28.5\%) $14(33 \%), 4(10 \%)$ and one patient respectively.

Conclusion: Our study suggests high prevalence of nHPT among patients referred to metabolic bone service with confirmed bone health issues. Nearly a third of patients have nHPT in this secondary care setting and a quarter have already suffered fragility fractures. These patients carry high comorbidity, polypharmacy and osteoporosis burden. Management of such patients is challenging owing to complex interplay of various ailments. Bone active agents are required for nearly two-thirds of this group. Though the natural course of nHPT is an area of active research, our data adds to the growing body of evidence that this is no a benign condition with particularly high fracture burden and poor bone quality. 
nHPT is perhaps responsible for the onset and progression of the similar osseous complications as described in classical PHPT. Further longitudinal studies are required to help devise best management plan to mitigate against the skeletal encumbrance of nHPT.

Disclosure of Interests: None declared

DOI: 10.1136/annrheumdis-2021-eular.1095

\section{AB0611 OSTEOPOROSIS IN RHEUMATOID ARTHRITIS: A NECESSARY EVIL?}

S. Athimni ${ }^{1}$, S. Bouden ${ }^{1}$, A. Ben Tekaya ${ }^{1}$, A. Dghais ${ }^{1}$, O. Saidane ${ }^{1}$, R. Tekaya ${ }^{1}$, I. Mahmoud', L. Abdelmoula ${ }^{1} .^{1}$ Charles Nicolle Hospital, Rheumatology, Tunis, Tunisia

Background: Rheumatoid arthritis (RA) is a chronic inflammatory disease that is characterized by local and general bone loss. Osteoporosis (OP) is one of the most frequent comorbidities associated with RA. Many factors are incriminated in bone loss in RA such as inflammation, glucocorticoid (GC) use, and immobility. Objectives: -To determine the prevalence of OP in a population of actual RA patients.

-To determine the risk factors of bone mineral density (BMD) reduction

Methods: One hundred-fifty-two RA followed in the rheumatology department between 2015-2020 were enrolled in the study. The diagnosis of RA was established according to the American College of rheumatology/European League Against Rheumatism (ACR/EULAR) criteria 2010. BMD in lumbar spine and total hip was systematically measured in the recruited patients. Measures were taken with dual-energy x-ray absorptiometry (DEXA), and age-specific values were compared with pooled values from a local population of healthy subjects free from earlier fractures.

Results: The mean age was $42.7 \pm 13$ years. The sex ratio $M / F$ was 0.24 . The mean onset disease was $6 \pm 1.8$ years. Fifty-sex patients $(36.3 \%)$ were receiving conventional treatment DMARDs and $96(63.6 \%)$ were under biological treatment. $35.5 \%$ were taken steroids with mean doses at $7.7 \pm 3.3 \mathrm{mg} / \mathrm{day}$. RF and ACPA were positive respectively in $87.3 \%$ and $82.4 \%$ of the patients. The mean disease activity score DAS28CRP was $4.8 \pm 2.7$.

Sixty-eight point eight $68.8 \%$ of the RA population had bone loss: $37.5 \%$ had osteopenia and $31.3 \%$ had OP. Regarding the OP group, sex ratio M/F was 0.45 . The mean age was $42 \pm 5.3$ years. Among the 31 women, $77.4 \%$ had postmenopausal OP. The BMI average was $31.18 \pm 6.19 \mathrm{~kg} / \mathrm{m}^{2}$. Fifteen patients $(33.33 \%)$ had OP in the hip site and 20 patients had OP in the lumbar site $(48.8 \%)$. Ten patients had both trabecular and cortical OP.

Advanced age, glucocorticoid use and high DAS28CRP were independent risk factors for OP (respectively $p=0.04, p=0.02$ and $p=0.01$ ). Body mass index, smoking, disease duration high Health Assessment Questionnaire (HAQ) score $(p=0.545)$ and smoking $(p=0.326)$ were not associated with high risk of OP. The biological treatment was not a protective factor in OP $(p=0.972)$. All the population subjects were free from earlier fractures, the fractural risk estimated by dint of the mean FRAX ${ }^{\mathrm{TM}}$ score was at $1.4 \pm 2.3$.

Conclusion: Previous studies estimated that, approximately, osteoporosis affected one-third of RA patients which is in concordance with our study. Advanced age, glucorticoid treatment and severe disease were the most common risk factor in our study.

Disclosure of Interests: None declared

DOI: 10.1136/annrheumdis-2021-eular.1235

\section{AB0612 THE FRACTURE PREVENTION UNIT OF THE VIRGEN MACARENA HOSPITAL REDUCES THE GAP IN THE MANAGEMENT OF OP, PARTICULARLY IN MALES AND MEETS IOF/ESCEO QUALITY STANDARDS}

B. Hernández-Cruz ${ }^{1}$, F. J. Olmo Montes ${ }^{2}$, M. J. Miranda García ${ }^{2}$, M. D. Jimenez Moreno $^{2}$, M. A. Vázquez Gómez ${ }^{3}$, M. Giner García ${ }^{3}$, M. A. Colmenero Camacho ${ }^{2}$, J. J. Pérez Venegas ${ }^{1}$, M. J. Montoya García ${ }^{3} .{ }^{1}$ Hospital Universitario Virgen Macarena, Rheumtology, Sevilla, Spain; ${ }^{2}$ Hospital Universitario Virgen Macarena, Internal Medicine, Sevilla, Spain; ${ }^{3}$ University Medical School, Internal Medicine, Sevilla, Spain

Background: The Virgen Macarena University Hospital belongs to the Public Health System of Andalusia and serves 481,296 inhabitants in Seville, Spain. In 2018 the Fracture Liaison Service switched to a multidisciplinary unit.

Objectives: To describe FLS, to know the characteristics of patients with emphasis on gender differences and to know the completion of International Osteoporosis Foundation quality standards.

Methods: Prospective, observational, analytical, research of usual clinical practice. All the consecutive patients attended from May 2018 to October 2019, $\geq 50$ years, with a fragility fracture (occurred in the previous 24 months) were included. The study was approved by the Ethics Committee, Code 1084-N-16.
Results: Our FLS is a type A multidisciplinary Unit, with a high level of intervention in the evaluation, estimation of fracture risk and fall risk, treatment prescription and follow-up of the patients. We included 408 patients, $80 \%$ females, one third with $\geq 80$ years. Fragility fractures recorded in 328 women were hip $(132,40 \%)$, clinical vertebral $(81,25 \%)$ and no hip no vertebral ( 115 $35 \%)$. Those recorded in 82 males were hip (53, 66\%), clinical vertebral $(20$ $24 \%)$ and no hip no vertebral $(9,10 \%), p=0.0001$. Males had a higher rate of secondary causes of OP, drinker, and smoking. The most relevant gender difference was the low percentage of patients receiving pre-FF OP treatment. Forty-nine (16\%) women versus $9(7 \%)$ males had received it at some point in their life, $p=0.04$. Two hundred and seventy-one (86\%) women vs 48 males $(63 \%)$ had received it at after their FF in their reference unit, and all them were treated after the FLS evaluation. The probability of a male not receiving prior treatment was $2.5(95 \% \mathrm{Cl} 1.01-6.51) ; \mathrm{p}=0,04$. This probability was 0.64 (0.38-1.09) after the FF. After twelve months of follow-up in FLs, 96\% continued treatment, with no differences between men and women. The completion of IOF quality standards was bad (red light) for patient identification items and FLS reference time. It was poor (amber traffic light) for initial OP screening standard and was good (green light) for the remaining 10 indicators. The completion of IOF quality standards was bad (red light) for patient identification items and FLS reference time. It was poor (amber traffic light) for initial OP screening standard and was good (green light) for the remaining 10 indicators (Figure 1).

\section{Percentage of compliance with quality of care standards.}

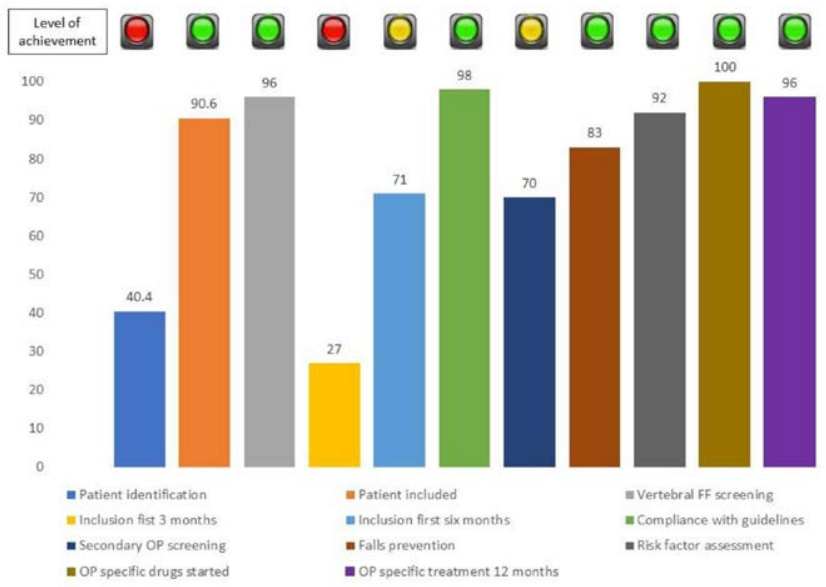

Figure 1.

Conclusion: The FLS is a multidisciplinary type A. Its operation has narrowed the gap in diagnosis, treatment, and follow-up of FF patients, especially males. It is essential to improve patient recruitment, reduce referral times and increase the overall assessment of the patients.

\section{REFERENCES:}

[1] Ganda K. et al. Models of care for the secondary prevention of osteoporotic fractures: a systematic review and meta-analysis, Osteoporos Int 2013:24:293-406.

[2] Javaid MK et al. A patient-level key performance indicator set to measure the effectiveness of fracture liaison services and guide quality improvement: a position paper of the IOF Capture the Fracture Working Group, National Osteoporosis Foundation and Fragility Fracture Network. Osteoporos Int. 2020 Jul;31(7):1193-1204.

Acknowledgements: Spanish Society of Research in Mineral and Bone Metabolism for its support through the competitive project FLS Excellence 2018 to obtain a training grant from the case management nurse.

Disclosure of Interests: Blanca Hernández-Cruz Speakers bureau: Sociedad Española de Reumatología, Abbvie, Roche, Bristol, MSD, Lilly, Pfizer, Amgen, Sanofi, Consultant of: Abbvie, Lilly, Sanofi, STADA, UCB, Amgen, Galapagos. Grant/research support from: Fundación para la Investigación Sevilla, Junta de Andalucía

Fundación Andaluza de Reumatología, Sociuedad Española de Reumatología. Francisco Jesús Olmo Montes: None declared., Maria José Miranda García: None declared., María Dolores Jimenez Moreno: None declared., María Angeles Vázquez Gómez: None declared., Mercedes Giner García: None declared. Miguel Angel Colmenero Camacho: None declared., José Javier Pérez Venegas: None declared., María José Montoya García: None declared. DOI: 10.1136/annrheumdis-2021-eular.1448 